\title{
A Systematic Review for Service Humanoid Robotics Model in Hospitality
}

\author{
Jiaji Yang ${ }^{1}$ (D) Esyin Chew ${ }^{1}$
}

Accepted: 31 October 2020 / Published online: 24 November 2020

(c) The Author(s) 2020

\begin{abstract}
Nowadays, the Fourth Industrial Revolution has brought artificial intelligence to the forefront, and more and more intelligent robots begin to be used in the hospitality industry. In this study, the application of service humanoid robots in the hospitality industry is investigated based on Cardiff Metropolitan University EUREKA Robotics Lab's robot as reported by Lab (in Eureka robotics lab, 2017, https://www.cardiffmet.ac.uk/technologies/Pages/EUREKA-Robotics-Lab.aspx). The research ontology of this study is post-positivism. The research philosophy of this research is phenomenology. Phenomenological studies have indicated that this phenomenon can only be truly understood and experienced through subjective immersive research directly involving researchers, and the interaction among researchers is an integral part of the research. In this study, the data are collated through case researches and experimental interviews. Finally, Some proposals for transforming the traditional hospitality industry into the direction of intelligence is summarized. In future research, a technical model combining artificial intelligence will be further developed.
\end{abstract}

Keywords Service Humanoid robotics · Robot in hospitality · Artificial intelligence

\section{Introduction}

\subsection{The Background of Intelligent Humanoid Robotics for Hospitality}

The First Industrial Revolution that began three hundred years ago was an unprecedented period of technological, economic, and social change that completely transformed British culture from a largely rural, static society with limited production and division of labor into the world's first modern industrial society [4]. Nowadays, the Fourth Industrial Revolution is continuously characterized by the emergence of artificial intelligence and automated robots [14]. The Fourth Industrial Revolution is disrupting and changing the transformation of the entire ecosystem of education and businesses, from operation production to service and hospitality [31]. Although most hospitality industries still maintain the traditional business model, Artificial Intelligence (AI) and

Jiaji Yang

JYang@cardiffmet.ac.uk

1 EUREKA Robotics Lab, Cardiff School of Technologies, Cardiff Metropolitan University, Western Avenue, Llandaff, Cardiff CF5 2YB, UK automated robots have emerged in the hospitality industry and made subtle changes. Service humanoid robots have been introduced for hospitality in China, Japan, and Malaysia since $2016[10,41,42]$.However, how can these humanoid robots be introduced to the hospitality sector and what are the possible impacts around business processes and ethical-privacy-legal agenda still require to be further investigated. Besides, some researchers stated that highly intelligent humanoid robots may face ethical and moral challenges. There are still other complications such as whether humanoid robots can be regarded as legal persons to assume legal obligations and how robots can get along better with humans and live in the same environment. Since 2014, the Ministry of Economy, Trade, and Industry of Japan has issued a series of robot policy guidelines to solve the commercial and safety problems of the "next generation of robots" [25]. They proposed to establish "Tokku" Robot Experience Test and Development Zone (RT Zone) and another special zone where humanoid robots and humanoid robots coexist peacefully considering the deregulation of robots in RT Zone [44]. The ability to solve the problem of robots in business processes and ethicsprivacy-law by mimicking the RT Zone in Wales is also one of the main considerations in this study. 


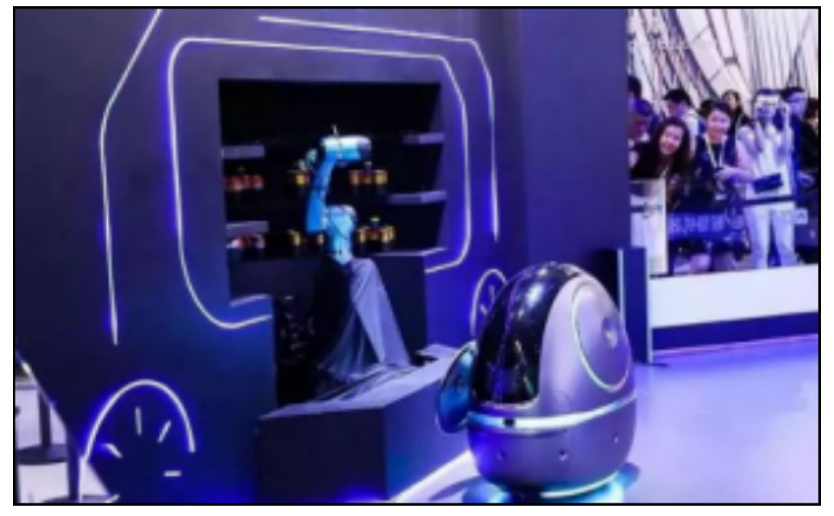

Fig. 1 Robot of China's Alibaba AI Lab [40]

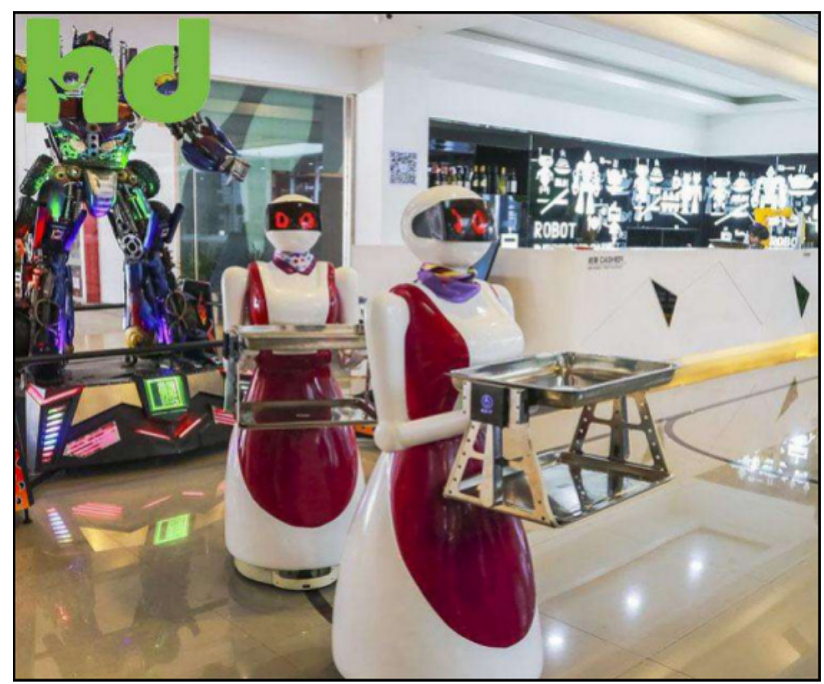

Fig. 2 Smart restaurant [17]

A hotel robot was launched in China's Alibaba AI Lab. All the processes of the experimental robots from delivering the meal to washing the clothes to the guests are conducted by the guest by a voice command robot (Fig. 1).

Intelligent restaurants have emerged in China. Consumers can order food through the intelligent system or pay attention to the public number. After order payment, the intelligent stirfrying machine completes the actions such as dish making, potting, and cleaning. Ultimately, seven types of equipment during the process of cooking dishes from automatic feeding, automatic stir-frying, to automatic cleaning only need one person to operate. Cargo Intelligent Kitchen will replicate mature models into commercial blocks, office buildings, community and enterprise canteens, and other scenes in the future to follow its innovative attempt to integrate intelligent technology with catering scenes, contributing to serving more people and meeting increasing personalized needs of consumers (Fig. 2).

As the world's first robotic Hotel certified by Guinness World Records, Henn-na has been operating in Japan since

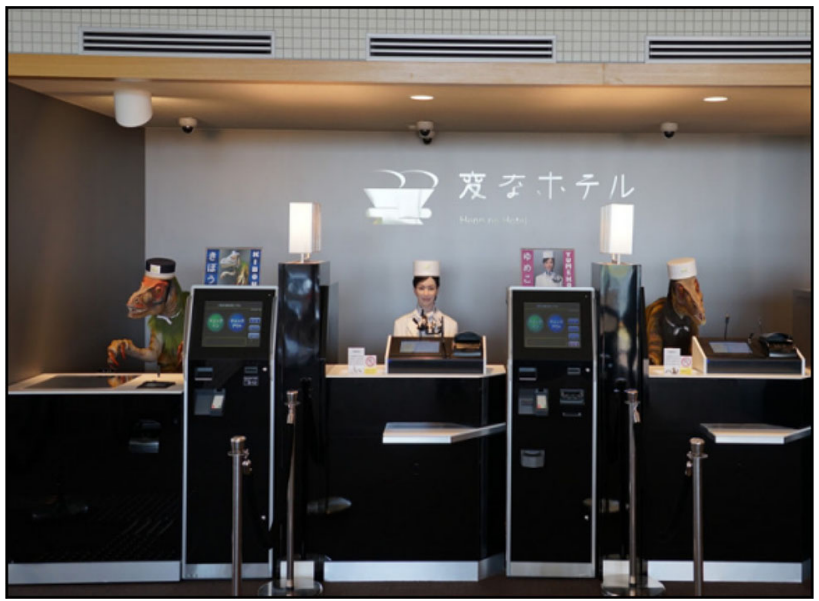

Fig. 3 Henn-na in Japan [5]

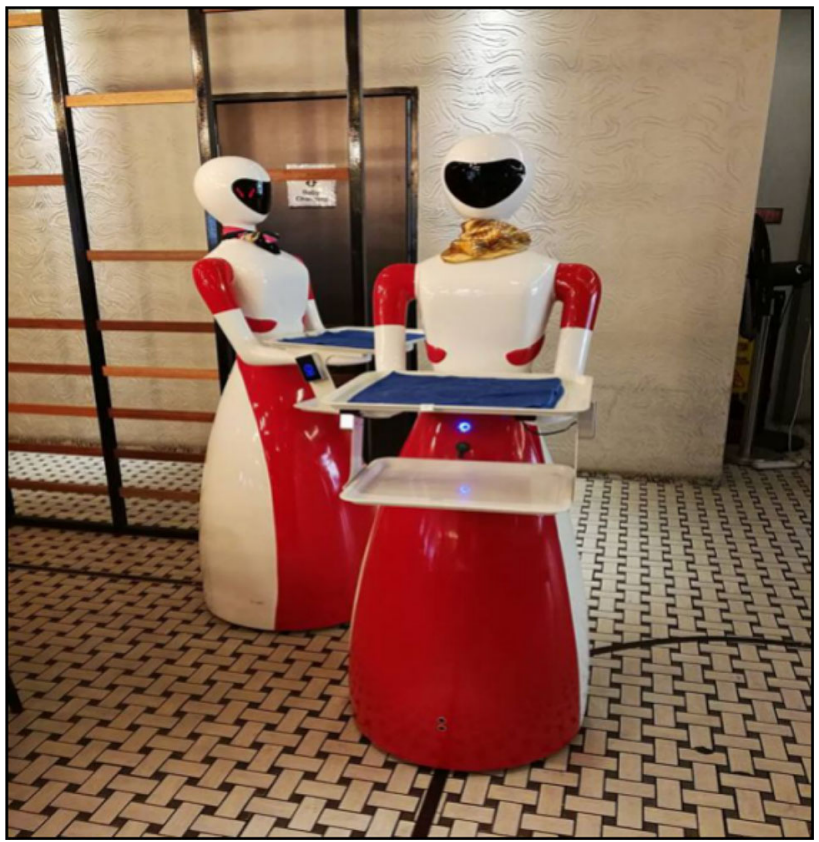

Fig. 4 Robot in Malaysia Nam Heong restaurant [34]

2015. Almost all the hotel's receptionists, messengers, cleaners, and baggage handlers are robots (Fig. 3).

Recently, some coffee houses in Malaysia have begun to employ robots as formal employees to serve consumers (Fig. 4).

In summary, intelligent humanoid robots have been used in various hospitality industries and serve as human beings for employees. The original intention of the introduction of intelligent robots is to better attract customers and reduce the cost of the service staff in the hospitality industry. However, Japan's Henn-na "Strange" Hotel has laid off half of its 243 robots after they created more problems than they could solve, as first reported by The Wall Street Journal [41]. This failed case sounded the alarm for introducing robots to the tra- 
ditional hospitality industry. For example, chafing dish robots have been introduced in Chongqing, Fuling, Yongchuan, and other local chafing dish shops since 2015; however, these robots have disappeared because consumers have lost their freshness. The head of the chafing dish restaurant stated that a robot can hold up half of the waiters while it cannot completely replace the waiters. Waiters are still required to bring the food to the table for the robots to deliver food to a customer's table. Although robotic waiters are not emotional or need no training, they are unable to communicate freely with customers and cope with emergencies, with obvious shortcomings [35]. These failed cases do not indicate that robots are not suitable for the development of this field while they suggest that robots should focus on the development of data analysis and service intelligence. Intelligent technology has brought a lot of challenges and problems, as well as changes to the traditional industries. Therefore, how to predict and solve these problems more reasonably is a major challenge for intelligent technologies such as robots. Focusing on the challenges of the introduction of intelligent technologies, a rational framework for the application of intelligent robots in the hospitality industry is developed in this study.

\subsection{Problem Definitions and Research Motivation}

As described in the previous section, intelligent robots face many challenges in this context. More and more intelligent technologies such as AI, robotics, the Internet of Things, and biotechnology are redefining the entire industry and creating new industry management models [37]. The traditional hotel industry faces challenges such as labor shortages, an increase in the number of international tourists, and a large number of consumer data [3]. The main motivations of this paper are how the intelligent humanoid robots can better adapt to the hotel industry, how the problems and challenges faced by the traditional hotel industry can be solved, and how new business models can be created.

How to better integrate AI humanoid robots into the hospitality industry and avoid similar incidents happening again in Henn-na hotel of Japan are the main concerns of this study. According to the background and environment experienced by the service humanoid robots are, the research defines the following problems:

(1) Are there any legal restrictions on AI robots in various countries? What are the advantages and disadvantages of the existing intelligent robot hosting cases?

(2) Are there loopholes in the traditional hospitality industry? Can Intelligent Robot Hospitality improve user experience through models?

(3) Which humanoid robots are most suitable for hospitality (such as NAO and SANBOT) and what artificial intelligence technologies (knowledge-based or case-based reasoning) are used by robots or humans to manage which operations, tactics, or strategic business decisions? Which voice engines will be used for human-computer interaction (Google Speech or Microsoft Azure), and how to integrate or customize the service management framework of intelligent robots in the hospitality industry to influence the business process of the intelligent hospitality industry?

This study aims to solve the problem of the above definitions through a large number of investigations and field visits.

\subsection{Aim and Objectives}

Corresponding objectives have been formulated in this study through the detailed definition and clarity of the problem in the previous section. Based on the existing capability of the EUREKA Robotics Lab at Cardiff School of Technologies, a customer-servicing humanoid robotic programme is designed to enhance hospitality services. Depending on the diffusion of high-level knowledge from the University, the growth of the hospitality is promoted by the skills and technologies of challenging and transforming business services and processes. Aiming to successfully translate the research and innovative business processes into new improved and customised commercial products and services, the available Al-driven robot technology is transferred to the hospitality with the following objectives:

(1) To investigate appropriate examples and implementation models of humanoid service robots in major countries worldwide (China, Japan, Korea, and Germany) through legal privacy and ethical governance.

(2) To explore and discover current and traditional hospitality processes, the customer maturity model, and the further enhancement through AI.

\subsection{Research Constraints}

The amount of data collected by the research institute in a developing innovative technology industry is limited to a certain extent. Besides, the prototype designed in this study will only be tested on a single type of robot because of equipment limitations (SANBOT [36]).

\section{Literature Review}

\subsection{Literature Review Design and Method}

The objectives proposed by the Institute mainly focus on using robot-related technologies to improve and enhance 
the business model of traditional hotels. Besides, the ethical governance and legal privacy involved in an innovative technology applied in the service industry are the guarantees that technology can continue to operate in the future. This requires research and comparison of a large number of existing cases and implementation models. Moreover, the introduction of new business processes and strategies has strengthened the traditional business model based on traditional business processes and strategies. In this study, a systematic literature review according to the above objectives is conducted to solve the following problems:

(1) What are the measures and challenges in the case of each country?

(2) From what aspects can intelligent robots and intelligent service technologies enhance the traditional model?

(3) What are the existing robotics technologies utilized in the service industry?

The Scopus database for a preview analysis of the literature review is employed in the study. Scopus is Elsevier's abstract and citation database launched in 2004. All journals in the Scopus database are reviewed each year to ensure that high-quality standards can be maintained. A series of keyword search strings are used in the theme to determine the research area of the robot for service.

(1) TITLE-ABS-KEY ( robot AND service )

(2) TITLE-ABS-KEY ( robot AND service ) AND ( LIMITTO ( SUBJAREA , "COMP" ) OR LIMIT-TO ( SUBJAREA , "ENGI" ) OR LIMIT-TO ( SUBJAREA , "MATH" ) OR LIMIT-TO ( SUBJAREA, "SOCI") OR LIMIT-TO ( SUBJAREA , "BUSI") OR LIMIT-TO ( SUBJAREA, "PSYC") OR LIMIT-TO ( SUBJAREA, "MULT") OR LIMIT-TO ( SUBJAREA, "ECON") )

(3) TITLE-ABS-KEY ( robot AND service ) AND ( LIMITTO ( SUBJAREA, "COMP") )

(4) TITLE-ABS-KEY ( robot AND service ) AND ( LIMITTO ( SUBJAREA, "ENGI") )

(5) TITLE-ABS-KEY ( robot AND service ) AND ( LIMITTO ( SUBJAREA, "MATH") )

(6) TITLE-ABS-KEY ( robot AND service ) AND ( LIMITTO ( SUBJAREA, "BUSI") )

(7) TITLE-ABS-KEY ( robot AND service ) AND ( LIMITTO ( SUBJAREA , "BUSI") ) AND ( LIMIT-TO ( SUBJAREA, "ECON") OR LIMIT-TO ( SUBJAREA, "PSYC"))

In this study, a large number of references were retrieved using the above search strings. The references are screened in this section. The screening process is illustrated in Fig. 5 Through the first group of keywords (robot and service), 11,698 related articles were searched. These documents are designed for computer science, engineering, mathematics, sociology, business, economics, psychology, interdisciplinary, and other fields. The fields of hospitality and computer science are combined because the main research area belongs to the subfield of service science. Therefore, the first screening of articles was conducted, excluding a total of 700 articles that were not related to the hospitality industry. In the remaining articles, the research area was narrowed down. According to the research objectives, the research area was reduced to business, management, economics, econometrics, and finance. After narrowing the scope, the remaining number of articles is 200. Finally, the relevant cases and literature suitable for the purpose of this study are found out through manual screening with 200 articles. Manual screening and auditing of methodological quality measurements were adapted on Joanna Briggs Institute [15], and the key assessment tools included JBI Critical Appraisal Checklist for Systematic Reviews and Research Syntheses. (Fig. 6). According to the audit tools, the following issues are considered in the audit:

(1) Is the review question clearly and explicitly stated?

(2) Were the inclusion criteria appropriate for the review question?

(3) Was the search strategy appropriate?

(4) Were the sources and resources used to search for studies adequate?

(5) Were the criteria for appraising studies appropriate?

(6) Was critical appraisal conducted by two or more reviewers independently?

(7) Were recommendations for policy and/or practice supported by the reported data?

It can be seen that the introduction of the JBI critical tool includes the requirements for the exclusion of articles and peer review in the process of exclusion. The process of peer review is that the researchers first screen the literature, and then the peers double-check the screened literature for compliance with the JBI exclusion criteria tool. Since the research object is mainly humanoid robots, when the researchers exclude, they default to follow the principle of humanoid robot priority. In addition, in order to ensure the novelty of the research results, the included studies follow the priority of selecting the latest results of the past five years.

\subsection{Challenge of Traditional Hospitality}

The traditional hospitality industry is facing tremendous changes such as the increasingly fierce competition and the increasing demand from customers. Besides, there are difficulties in the management of human resources due to the bad attitude of some employees [39]. Since the hospitality industry's business process involves high-frequency inter- 


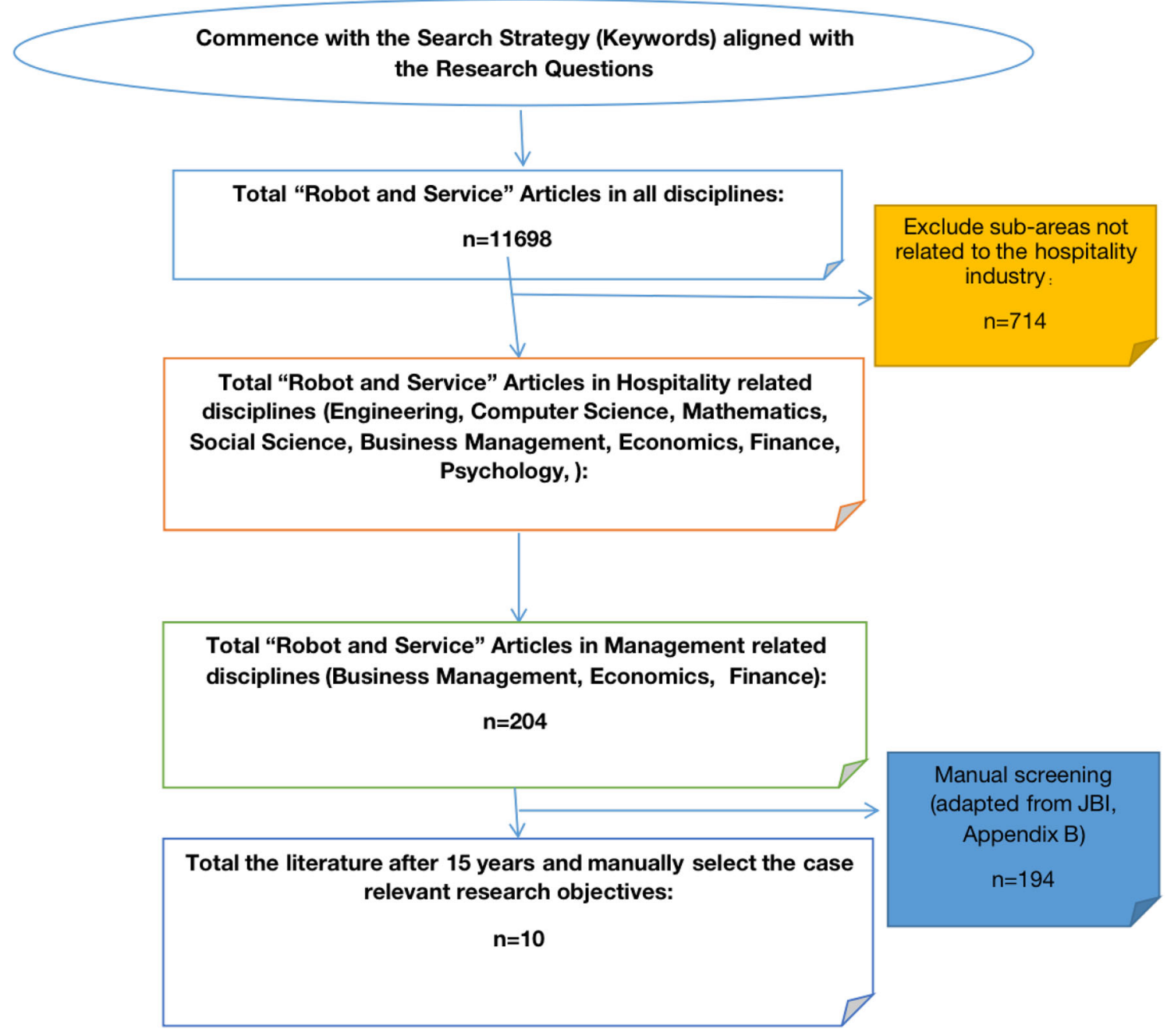

Fig. 5 Literature case screening process

action with customers, the service quality of employees is the key to ensuring the long-term management success of hospitality $[27,39]$. Ostrom also pointed out that both the consumer's consumption habits and the management of the service industry have undergone tremendous changes in this era of high-speed information communication technology. In addition to improving the service quality of employees, he also mentioned the use of big data to promote services [27]. Most research indicated that traditional service industries should apply technologies to continuously stimulate service innovation, especially in improving employee service quality and staff management. The Fourth Industrial Revolution brought an opportunity for the introduction of humanoid intelligent robots in the service industry [29]. Humanoid intelligent robots that can replace human services are able to use technical means to deal with big data that humans cannot handle to improve the service quality. Besides, the service industry can collect data generated by consumers through robots to avoid the risk that data cannot be effi- ciently integrated and utilized by traditional non-digital data collection methods in the traditional service industry. In the management of robots, the attitude of the robot is based on the behavior imparted by the technical means, and managers do not have to worry about the robot's attitude shifting in the wrong direction. Reasonable and effective communication with employees is used in the traditional hotel industry staff management to obtain high service levels and positive service attitudes [39]. However, it is a huge challenge for managers, both in terms of effective employee supervision and improving service quality [39]. It is much easier to manage robots with specific techniques than those with rich emotions. For example, managers can easily modify and customize the robot's programs or tasks without considering whether the robot is willing to accept such tasks. Although the introduction of humanoid robots has reduced the requirements for managers, exploring a suitable technical means has also become a major challenge for this institute. 
Besides, some countries and regions face a labor shortage due to the aging of the global population. For example, a labor shortage in Taiwan brings great potential and motivation for the introduction of intelligent robots [20]. The nature of hotel work is defined as an entry-level job, which provides seasonal job-time employment opportunities for employees in the industry [1]. Wei [43] further pointed out that entrylevel work, especially unskilled service tasks, will gradually be replaced by automated robots. This robotic technology solution enables hospitality to complement human services by introducing new employee-based technology interfaces in the self-service delivery process [11]. Therefore, a theoretical basis for the research institute to use intelligent robot technology instead of manual services is provided by these viewpoints to reduce the cost of manual services and control the quality of services. In these studies, field survey methods were mainly used to obtain data. The problems and challenges faced by the traditional hospitality industry are summarized through the analysis of the data. The introduction of intelligent robots can solve these problems to a large extent. Besides, this view also paved the way for the next study in the article. Moreover, the traditional hospitality industry is moving towards a new model. Although the technology replacement manpower will bring great convenience to managers in terms of human resources, it also requires managers to choose the right technology to adapt to the mode of their own operation. At present, there has been a phenomenon in the market to replace labor with machines, such as KFC's self-service ordering platform. However, this does not suggest that the utility of the humanoid intelligent robot is similar to that of the self-service ordering platform. The robots studied in this study focus on meeting the psychologically and emotional needs of consumers (such as communication between robots and consumers).

\subsection{Innovative Cases with Service Robots}

It is essential for hospitality to maintain a competitive advantage in determining whether a hospitality company can develop in the future. Innovative service methods using IT capabilities can provide better solutions for maintaining a competitive advantage $[2,11]$. From another perspective, the introduction of new technologies can attract a large number of potential customers and use the curiosity of potential customers to help the service industry open up new markets. The existing smart technologies can be applied in the new technologies to make the features easier for existing customers. For example, knowledge-based or case-based reasoning can provide robots with technical support to implement a recommendation system. Therefore, new opportunities can be brought into the market through the introduction of humanoid intelligent robots. Besides, the use of new technologies also enables companies to adapt to changing environments and provide greater competitiveness to companies [19,38]. Kuo [20] collected 53 data on the market demand of hotels, revealing that robotic services can help hotels deal with seasonal employment. Although the study did not detail the return on investment in service robot development, it laid the groundwork for further research on the views of customers and other tourism stakeholders. Moreover, SWOT (Strength Weakness Opportunity Threat) analysis indicates that the promotion of service robots can be increased by the pleasure and curiosity of consumers, and the demand for service robots can be increased by the aging society. These viewpoints and conclusions are sufficient to verify that the challenges faced by the traditional hotel industry in the previous section can be solved by the promotion and application of service-oriented robots [20].

It is noteworthy that the study of robots in hospitality is very new and scarce, mainly descriptive, forward-looking, or speculative [16]. Therefore, new problems and challenges will be brought by the application of intelligent robots. Leung [22] pointed out that stakeholder-defined new hospitality owners revolve around revenue growth, service customization, operational efficiency, and indoor automation. Since there is a big gap between stakeholders and academia in the definition of the intelligent hotel, stakeholders do not know where to start when managing the intelligent hospitality industry. Caleb Solly [6] believed that users can also help robots when robots help users; meanwhile, users can give feedback to optimize the system. The feedback reflects not only the optimization of the robot system but also the satisfaction of customers. Chung's [7] study indicated that hotels in the hospitality industry want to collect customer feedback in real-time to immediately disseminate positive feedback and respond to unsatisfactory customers while they are still on the scene. Guests want to inform their experience without affecting their privacy. Stakeholders in the hospitality industry hope that intelligent robots can interact more with users. Besides, Rodriguez [32] concluded that the optimal distance between users and robots is $69.58 \mathrm{~cm}$. Specifically, interaction with a certain greeting mode can attract users to maintain a longer interaction time; robots with the active search are more attractive to participants. The interaction time is longer than that of passively searching robots, suggesting that robots should be designed to keep at a certain distance from humans and consider adding the ability to allow robots to actively identify customers and attract them. Bowen [3] claimed that robots will be an important asset for many hotel organizations by the 2030s. The demand for robots will be partly driven by labor shortages, as well as the need to communicate with an increasing number of international travelers and create memorable customer experiences through the effective use of data available to customers. The introduction of robotics technology will be a major interruption in the industry. Since success during this interruption 


\section{(अ)}

THE JOANNA BRIGGS INSTITUTE

JBI critical appraisal tools can also be used when creating Critically Appraised Topics (CAT), in journal clubs and as an educational tool.

\section{JBI Critical Appraisal Checklist for Systematic Reviews and Research Syntheses}

Reviewer Jiaij Yang

Date 2019 Jun 29

Author Aromataris et al. Year 2015 Record Number 001 .

1. Is the review question clearly and explicitly stated?
2. Were the inclusion criteria appropriate for the review
question?
3. Was the search strategy appropriate?
4. Were the sources and resources used to search for
studies adequate?
6. Were the criteria for appraising studies appropriate?
7. Was critical appraisal conducted by two or more
reviewers independently?
(11. Were there methods to minimize errors in data
appropriate?
9. Were the methods used to combine studies
appropriate?

Overall appraisal: Include $\square$ Exclude $\sqrt{ }$ Seek further info

Comments (Including reason for exclusion)

The hospitality industry is a sub-research field of service industry. The research mainly focuses on Hospitality industry.

\section{(C) Joanna Briggs Institute 2017}

Appraisal Checklist for Systematic Reviews and Research Syntheses

Fig. 6 Sample of inclusion screening using JBI 
will require redesigning service delivery systems, robots can create customer value with better products, lower prices, or both. Service delivery redesign will also maintain a highlevel Customer Service [3].

Besides, studies by Bowen [3] and Ivanov [16] have indicated that young people are more receptive to the novelty of intelligent robots than older people. From another perspective, this suggested that the promotion of intelligent robots is very significant. The intelligent robotic hospitality industry will probably be widely popularized. Nowadays, most of the robots used in the hospitality industry are human and humanoid. However, through the analysis of a sixdimensional customer willingness table, $\mathrm{Lu}$ [23] revealed that the closer the robot is to humans, the more disgusted and feared it will be by consumers. This demonstrated that we should not choose robots that are too similar to humans when choosing robots. Conversely, some cartoon or animallike robots can stimulate humans to feel comfortable about them. People are more willing to accept robots like pets than real people. In the case of Nakanishi's research [26], most participants admit that interacting with robots can produce positive responses. However, some participants claim that the hotel does not need such a system, which may be related to a value-added but not essential service. Humanoid robot interaction can increase customer satisfaction. For example, the warm attitude of humanoid robots can provide customers with a warm experience. Personal identification technology may be an essential key to a better service system. Women prefer to interact with robots. The verbal interaction of voice control speakers has a negative impact on service evaluation [26]. The research was limited and the researchers did not take advantage of the ability of robots to collect data for analysis and feedback, even though the results of the study were negative. The simple greeting model in the study did not give customers more knowledge and experience of robotics. This explains from another perspective that the service intelligence of the robot should be more biased towards data collection and analysis and decision making.

The idea that the verbal interaction of the voice-controlled loudspeakers has a negative impact is more desirable than the users in the Chung [7] case, where the robot's interactive content is protected to some extent. Human-Robot Interaction (HRI) is the focus of smart entertainment; Khan [18] emphasized that the benefits of combining other areas of the approach can benefit from meaningful social interaction with users because HRI is highly interdisciplinary. The results indicate that robot partners must express their intentions and skills as clearly as possible to avoid unmet expectations in order to obtain a positive experience. The motion and responsiveness of the robot often have a positive impact on the perception of the robot, and the simplified user interface can play a key role in enhancing the positive attitude towards non-humanoid robots.

\subsection{Al Application and Data Protection}

\subsubsection{Applied Al in Service Robotics}

The results of the Kuo [20] case study in Sect. 2.3 illustrate that both stakeholders and consumers are more likely to use the data to analyze and make decisions. This study believes that the decision tree classification algorithm in artificial intelligence can be effectively applied to service robots. A top-down recursive method is adopted in the decision tree learning. The basic idea is to construct a tree with the fastest decline in entropy value by using information entropy as a measure. The entropy value at the leaf node is 0 . It has the advantages of readability and fast classification, and it is supervised learning. Depending on the type of target variable, decision trees can be divided into two categories. In the discrete decision trees, the target variables are discrete, such as gender, male or female. In the continuous decision tree, the target variables are continuous, such as wages, prices, and age [33]. The core content of the decision tree is to calculate the entropy of different feature nodes. In information theory, entropy is a measure of the uncertainty of a random variable, indicating that the larger the entropy, the greater the uncertainty of the random variable [24]. Let $X$ be a finite number of discrete random variables whose probability distribution is:

$P\left(X=x_{i}\right)=p_{i}, i=1,2, \ldots n$

Then the entropy of the random variable $X$ is defined as:

$H(X)=-\sum_{i=1}^{n} p_{i} \log p_{i}$

There are random variables $(X, Y)$ with a joint probability distribution of:

$P\left(X=X_{i}, Y=y_{i}\right)=p_{i j}, i=1,2, \ldots n, j=1,2, \ldots m$

$H(Y \mid X)$ represents the uncertainty of the random variable $Y$ under the condition that the random variable $X$ is known. The conditional entropy $H(Y \mid X)$ of the random variable $Y$ under the given condition of the random variable $X$ is defined as the mathematical expectation of the entropy pair $X$ of the conditional probability distribution of $Y$ :

$H(Y \mid X)=-\sum_{i=1}^{n} p_{i} H\left(Y \mid X=x_{i}\right)$

The corresponding entropy and conditional entropy are called empirical entropy and empirical conditional entropy when the probability in entropy and conditional entropy is estimated from data (such as maximum likelihood estimation) 
[24]. The difference between the empirical entropy $H(D)$ of the set $D$ and the empirical conditional entropy $H(D \mid A)$ of the $\mathrm{D}$ under the given condition $A$ is the information gain, indicating the classification of the data set $D$ after the information of the feature $A$. The degree of deterministic reduction is defined as:

$\operatorname{Gain}(D, A)=H(D)-H(D \mid A)$

The operator can better obtain the factors affecting the quality of the user experience by calculating the information gain. Correspondingly, consumers can continuously improve the quality of experience through feedback data.

\subsubsection{Data Protection}

Big data is the foundation for the development of artificial intelligence systems. Artificial intelligence systems must follow normative guidelines for the use of personal data. Abuse of data or theft of privacy will be punished. Developers and researchers in the development of artificial intelligence must consider whether the program can protect citizens' data and privacy, whether they can treat each citizen's data equally, and whether they can guarantee the integrity of citizens' personal information and the use of non-public data to obtain the consent of the data owner. An appropriate balance between protecting the privacy of citizens and developing emerging technologies is required in legislation. There are many customary laws and regulations regarding the use of data, such as clear purpose, minimum use, public notice, and personal consent. Therefore, different countries have formulated the following laws and regulations for artificial intelligence and data protection:

In 2016, the National Artificial Intelligence R\&D Strategic Plan was released in the United States. The fourth strategy is used to ensure the safety of artificial intelligence systems. The plan proposed to adopt a series of measures such as enhancing the interpretability and transparency of artificial intelligence, building a trust system, and enhancing verifiability and identifiability to protect artificial intelligence systems from attacks for long-term artificial intelligence security and optimization [28].

In terms of privacy protection, the Federal Privacy Act of 1974 was the basic law for the protection of privacy, followed by the Federal Electronic Communications Privacy Act, the Interim Regulations on the Protection of Citizens' Internet Privacy, and Personal Privacy and State Information Infrastructure, and other laws [12].

As for data protection and personal privacy, a number of personal data protection directives such as the "Individual Protection for Personal Data Processing and the Free Flow of such Data" have been enacted in the EU to build a personal data protection system. In May 2009, the European Com- mission promulgated the "Recommendations on Privacy and Data Protection Principles in the Application of Radio Frequency Identification Technology", which clearly included information and transparency requirements, special requirements for retailers to use data, making clear identification of designers using identity tags. It is strictly prohibited to enter without an identity tag [8].

In 2016, the General Data Protection Regulations were adopted in the EU; it cannot include special categories of personal data in terms of automated decision-making, such as ethnicity, political opinions, religious beliefs, chamber members, biometrics, genes, health status, and sexual life. Otherwise, it will have a major impact on the provision of personalized services. In the same year, the General Regulations on the Protection of Personal Data was enacted in the EU, prohibiting all use of citizen personal data without consent or law [9].

Therefore, the principle of protecting the privacy and personal data must be adhered to under all circumstances In the era when personal data can be collected at any time. The EU Legal Affairs Committee recommends that standards for the protection of privacy, default privacy, informed consent, and encryption should be further refined when formulating policies for the field of artificial intelligence. According to the current German law, the ownership of data accumulated in vehicles is in principle owned by the owner [45].

\subsubsection{Intelligent Robot Anthropomorphization}

At present, how to treat artificial intelligence, especially specific intelligent robots, is more radical in many countries. Artificial intelligence is "personalized" and recognized with its legal personality by making major revisions to the formulation and implementation of laws.

As early as 2007, the Korean government established the Robot Ethics Charter and established guidelines for robots from the role and moral aspects. The Korean government's idea of developing this document is that intelligent robots are highly intelligent. It will inevitably provoke the resistance of intelligent robots and eventually lead to artificial intelligence to counteract human populations if humans improperly use or even "abuse" intelligent robots. On the surface, the original intention of the document was still to protect human beings while its provisions were to prevent humans from "abusing" robots; in addition to utilitarian considerations, it also contained a humanistic ultimate concern. If we only regard artificial intelligence as an object, how do we "abuse" it? Therefore, this document reflects the Korean government's tendency towards the subjectivity of human intelligence law [13].

In 2016, the Legal Affairs Committee of the European Commission submitted a motion to the European Commission to position the status of the most advanced automated 
robots as "electronic people", giving robots "specific rights and obligations", such as advocating artificial intelligence. The status of "worker" and the right to work are provided to them. Besides, the Legal Affairs Committee also recommends registration of intelligent automated robots for the purpose of setting up separate fund accounts for taxation, payment, and pensions. At present, the legal motion has not yet been passed while its impact cannot be underestimated. It will inevitably impact the traditional civil subject system when it is passed.

On October 28, 2017, the Saudi government officially granted the identity of the "female" robot "Sofia" Saudi citizen at the "Future Investment Initiative" conference held in Riyadh, the capital of Saudi Arabia. "Sofia" became the first robot in the world to be granted the status of a legal subject. All the above examples verify that some countries have begun to promote the recognition of the subjective status of artificial intelligence from the legal level based on factors such as culture, ethics, and technology.

\section{Consolidated Results of Secondary Research (Taxonomy)}

It can be revealed by investigating a large number of literature and cases that the traditional hospitality industry faces low quality of employees, difficult management of human resources, and the general lack of multilingual ability of employees to serve customers in different countries $[27,29,39]$. Besides, some regions and countries are encountering the challenges of labor shortage and the aging workforce [20]. The selected cases have a positive impact on solving the problems faced by the traditional hospitality industry $[2,11,19,38]$. Most cases $[2,3,11,19,38]$ indicate that these problems can be effectively solved by intelligent robotics.

However, most of the cases suggest that there is still the challenge of HRI, even though the situation faced by the traditional hospitality industry can be effectively improved by the robot. The conclusions of the case mainly focus on HRI. The results reveal that it is best to keep a distance of $69.58 \mathrm{~cm}$ when the customer communicates with the robot. Besides, adding a certain greeting mode during the interaction process can improve the interest and duration of customer interaction. The human-like design would cause customers to resent. The hospitality industry hopes that intelligent robots can obtain more valuable information from customers such as hotel experience feedback. Most customers want their privacy to be protected when interacting with the robot, and the robot's reactions and actions should not be too large or too conspicuous. Moreover, personal identification technology is an essential key to a better service system in some cases. Furthermore, the robot has been primarily verified to enhance

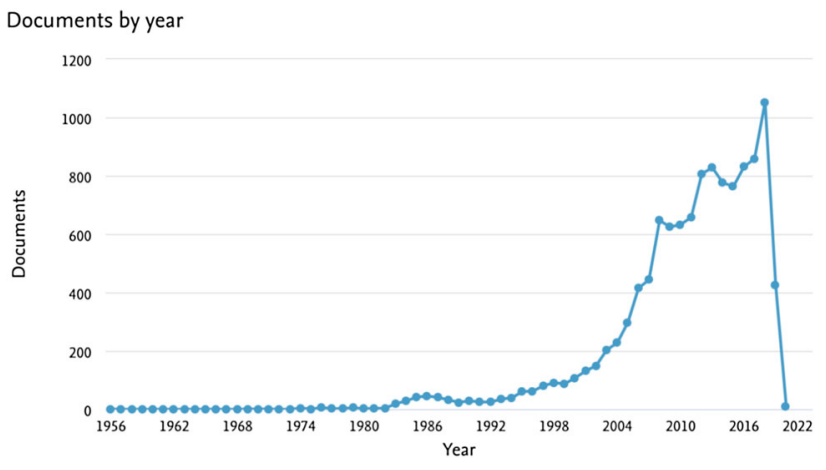

Fig. 7 Historical results in service robotics

the customer experience; the intent and task of the robot to enhance the user experience should be clarified.

At this stage, the legal and policy requirements for intelligent robots in various countries mainly focus on data protection, intellectual property protection, and the anthropomorphizing of intelligent robots. Some countries and regions want to anthropomorphize robots and provide them with the right to exist and enjoy citizens. Future ethical issues related to robots will be accountable. The robot will penalize its responsible person if it violates the law. However, how to define "its responsible person" is under debate.

The robot service-related content first appeared in the SEER, A SEquence Extrapolating Robot published in the reference [30]. In this article, a robot design that can recognize the changing sequence used in the communication industry is mainly described. Researchers believe that the idea of adapting robots to changing sequences or scenes is the original idea of AI. Since 1956, researchers have never stopped investigating robots for human services. As illustrated in Fig. 7, robots have been employed in more and more services since 1992. With the continuous development and improvement of artificial intelligence, more and more articles have been published. By 2018, the literature on robots in service has reached the highest point. In 2018, the article on robots in the service industry over Scopus exceeded 1000 articles.

To date, Germany, the United States, and China are the leaders in this field. Germany is a leader in computer science subjects for the research of robotics in the hospitality industry. As a leader in medicine, business management, and economicss, the United States is more concerned with the value that robots generate in this area. China focuses on engineering and mathematics research. The contributions of the UK, Japan, and Korea in these key areas are also evident (see Appendix A for further details). One expected result(Fig. 8 ) is that the relevant research is dominated by engineering and computer science (73\%), followed by mathematics (9.6\%), medicine (2.6\%), and social sciences. (2.3\%). This study focuses on business management and economics (1\%). 
Fig. 8 Scopus historical results by discipline

Fig. 9 Scopus historical results by publication venue

Fig. 10 Scopus historical results by country
Documents by subject area

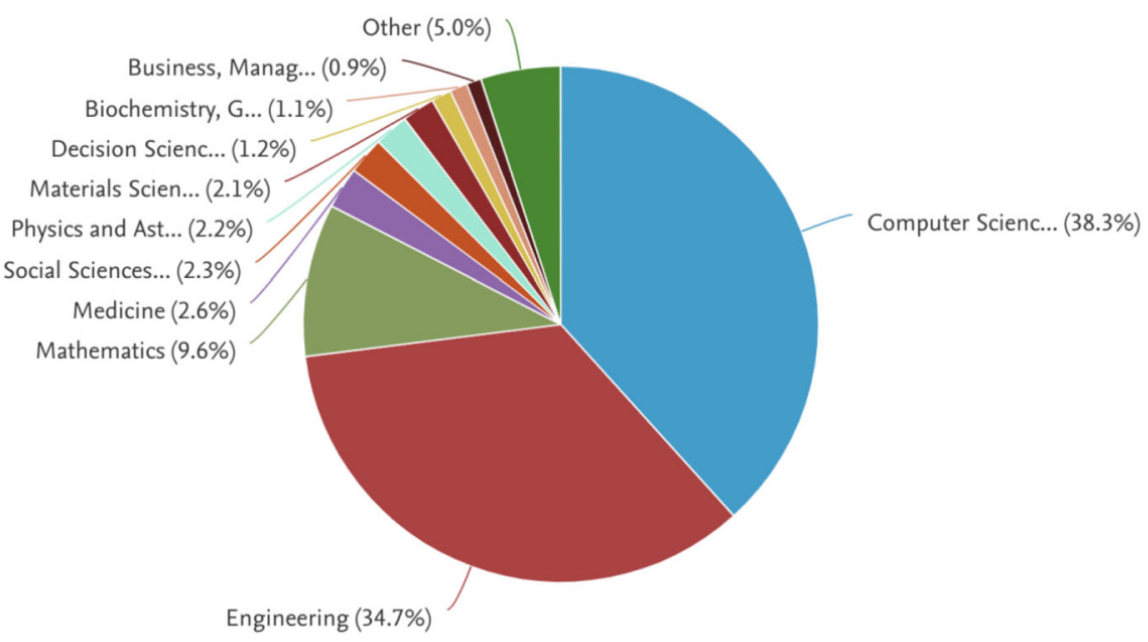

Documents per year by source

Compare the document counts for up to 10 sources.

Compare sources and view CiteScore, SJR, and SNIP data

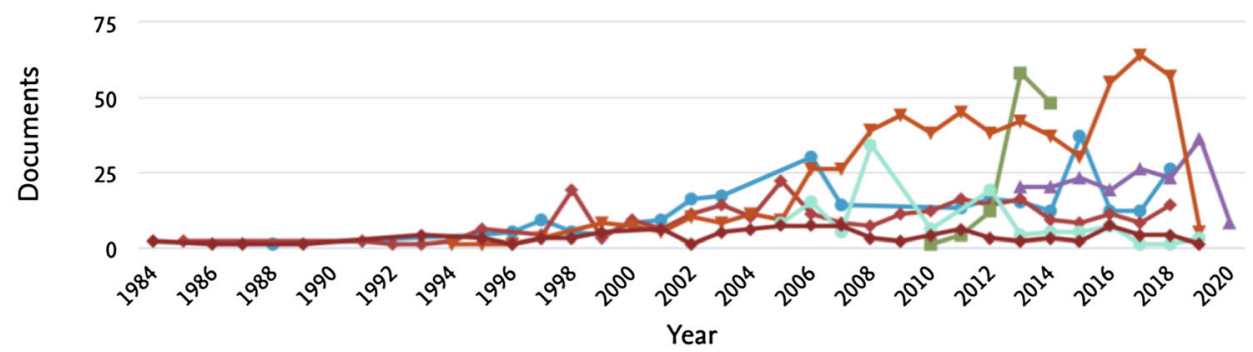

$\rightarrow$ IEEE International Conference On Intelligent Robots And Systems

$\rightarrow$ Proceedings IEEE International Conference On Robotics And Automation $\quad-$ Applied Mechanics And Materials

$\mp$ Advances In Intelligent Systems And Computing

* Lecture Notes In Computer Science Including Subseries Lecture Notes In Artificial Intelligence And Lecture Notes In Bioinformatics

$\rightarrow$ Springer Tracts In Advanced Robotics $\rightarrow$ Industrial Robot

\section{Documents by country or territory}

Compare the document counts for up to 15 countries/territories.

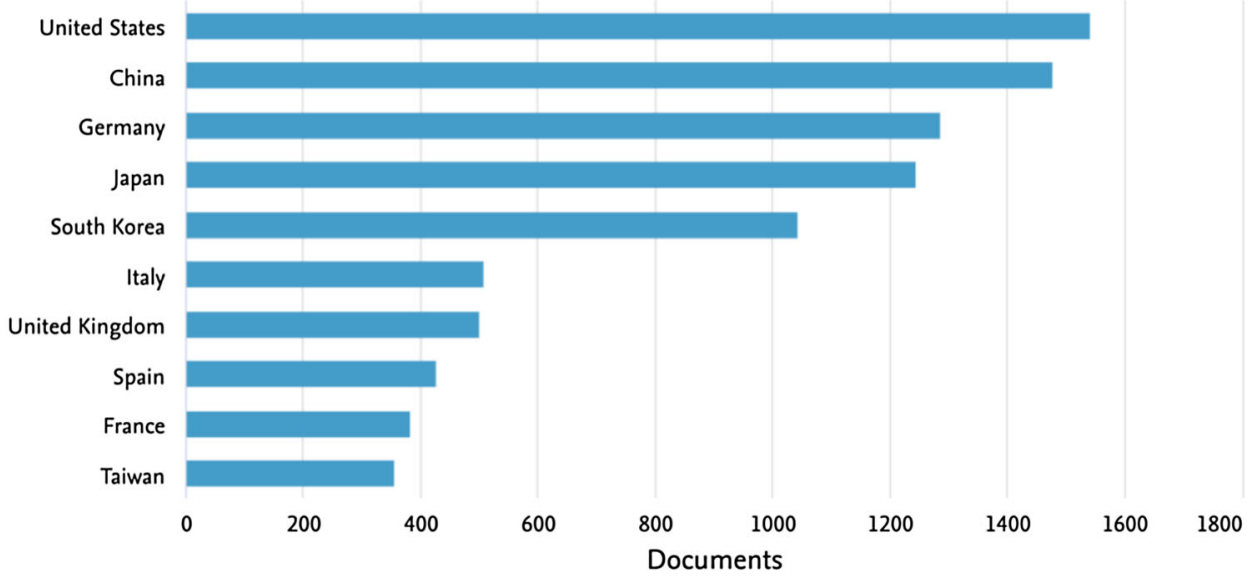


Fig. 11 Taxonomy of service robots by application areas and types of robots

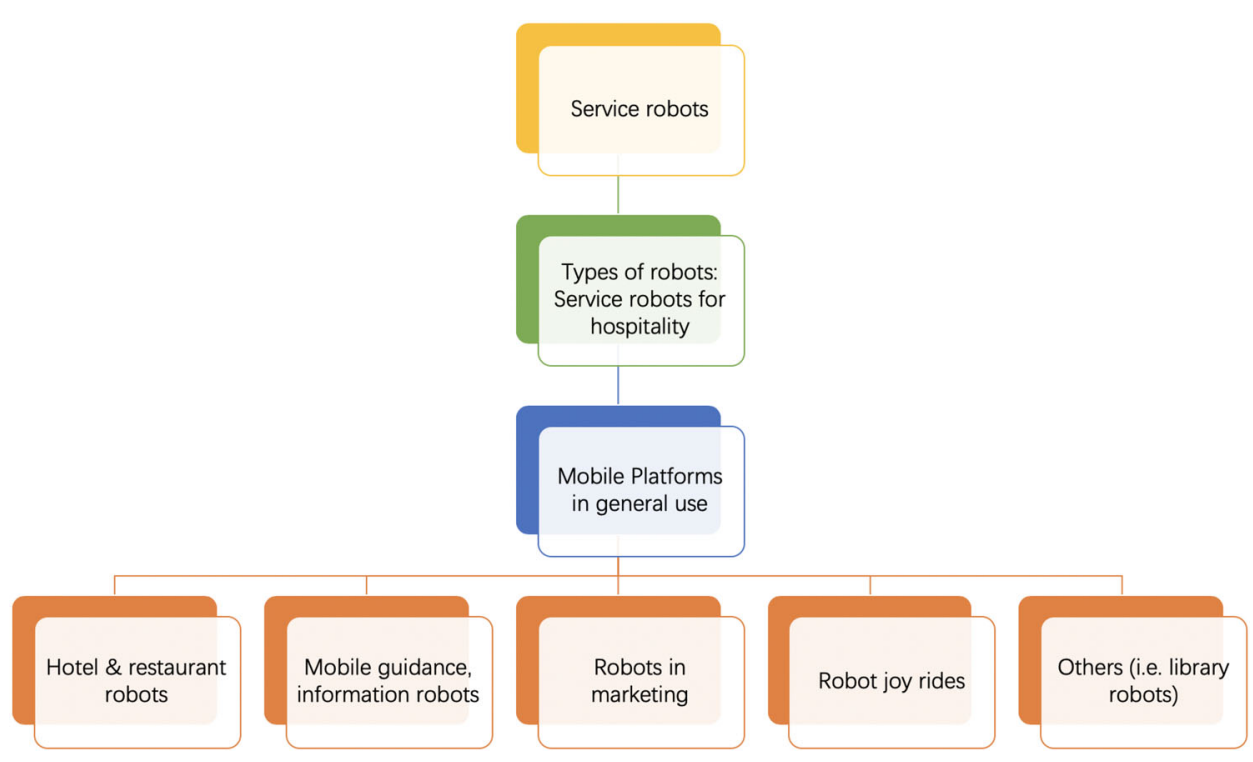

Most of the publications for service technology robotics are engineering, computer science, and mathematics, as illustrated in Fig. 9. The file types are mostly conference papers. Most publishers and conferences such as IEEE international conference on intelligent robots and systems are mainly concerned.As for intelligent robots and intelligent systems, the examples of applications around the world are less likely to remain in the experimental phase because the intelligent robot hospitality industry is in its infancy and has not yet developed a mature framework.

Overall, the United States and China have conducted the majority research in this area. The number of research publications in the countries such as United States, China, Germany, Japan, and South Korea is not much different (Fig. $10)$.

Based on the research objectives and cases, this research determines the taxonomy of robots involved in the literature. As shown in the yellow block in Fig. 11, the robot taxonomy that this research focuses on is the service robot. It is worth noting that the principle of the default priority of humanoid robots has been obeyed in all the following categories. On this basis, it is further restricted, as shown by the green block of Fig. 11. Restricted taxonomy includes the following subcategories. The main subcategories are hotel and restaurant robots, mobile navigation, information robots, marketing robots, entertainment robots, and library robots. These robots are shown as blue blocks in Fig. 11. The taxonomy is determined so that the researchers can find the corresponding literature and the types of robots involved in the research more quickly in future work.

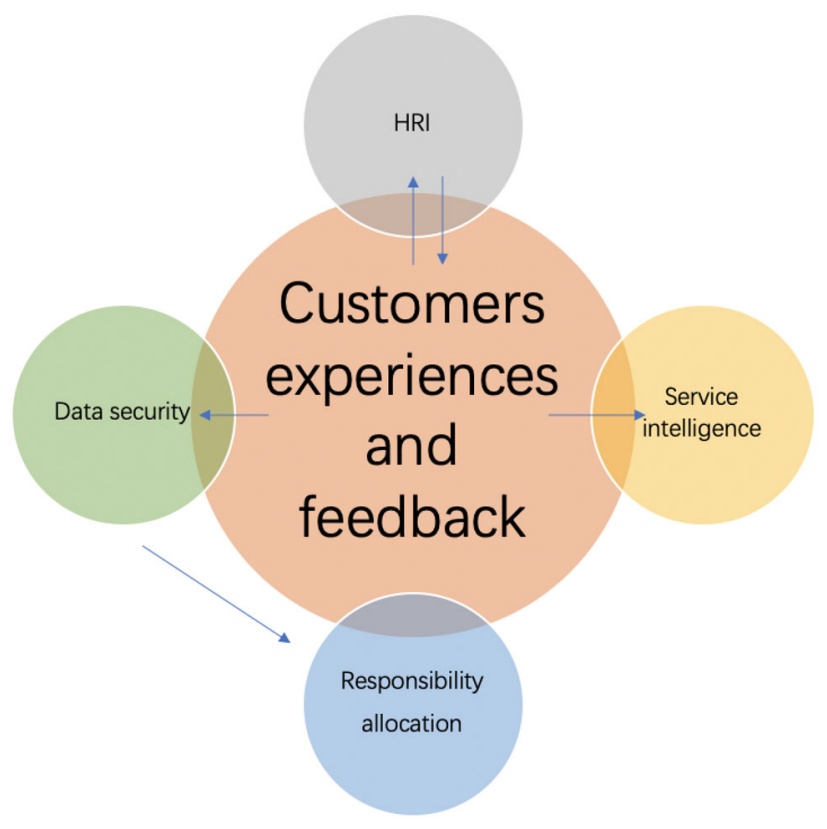

Fig. 12 Conceptual Model of Service Robotics in Hospitality

\section{Conclusion}

According to the conclusions drawn in this section, service robots in the hospitality industry should focus on four aspects: interaction between users and robots, artificial intelligence-based service models, user data protection, and responsibility allocation for robot management. These four aspects can connect and communicate through customer experience and feedback. Besides, user experience and feedback can be captured and updated through HRI, contributing to the enhancement of the robot's interaction model. The service intelligence model of robots is trained and continuously 
updated based on user experience and feedback. In terms of technology, the obtained user data is encrypted by using different encryption means. As for laws and regulations, the management and supervision of robots are managed using responsibility distribution to ensure the efficiency and accuracy of robot work. These together constitute the concept of service robotics in hospitality (Fig. 12). The conceptual model is helpful for researchers to design and develop an interactive framework that is applied in the hospitality industry. The issues involved in the conceptual framework will be further demonstrated in future work.

Open Access This article is licensed under a Creative Commons Attribution 4.0 International License, which permits use, sharing, adaptation, distribution and reproduction in any medium or format, as long as you give appropriate credit to the original author(s) and the source, provide a link to the Creative Commons licence, and indicate if changes were made. The images or other third party material in this article are included in the article's Creative Commons licence, unless indicated otherwise in a credit line to the material. If material is not included in the article's Creative Commons licence and your intended use is not permitted by statutory regulation or exceeds the permitted use, you will need to obtain permission directly from the copyright holder. To view a copy of this licence, visit http://creativecomm ons.org/licenses/by/4.0/.

\section{References}

1. Baum T (2006) Human resource management for tourism, hospitality and leisure: An international perspective. Cengage Learning EMEA

2. Bhatt GD, Grover V (2005) Types of information technology capabilities and their role in competitive advantage: An empirical study. J Manag Inf Syst 22(2):253-277

3. Bowen J, Morosan C (2018) Beware hospitality industry: the robots are coming. Worldw Hosp Tour Themes 10(6):726-733

4. Bruchey S (1970) The first industrial nation: an economic history of britain. Bus Hist Rev 44(4):550-551

5. BusinessTimes (2019) Half of the 243 robotic employees were laid off at the heinna robot hotel. https://www.businesstimes. cn/articles/136389/20190117/8437069778.html, accessed 26 Sep 2019

6. Caleb-Solly P, Dogramadzi S, Huijnen CA, Hvd Heuvel (2018) Exploiting ability for human adaptation to facilitate improved human-robot interaction and acceptance. Inf Soc 34(3):153-165

7. Chung MJY, Cakmak M (2018) "how was your stay?" : Exploring the use of robots for gathering customer feedback in the hospitality industry. In: 2018 27th IEEE International Symposium on Robot and Human Interactive Communication (RO-MAN), IEEE, pp 947-954

8. Commission TE (2009) Recommendations on privacy and data protection principles in the application of radio frequency identification technology. https://eur-lex.europa.eu/eli/reco/2009/387/oj, accessed 26 Sep 2019

9. Commission TE (2016) General data protection regulations. https://eur-lex.europa.eu/legal-content/EN/TXT/? qid=1569456579964\&uri=CELEX:32016R0679, accessed 26 Sep 2019
10. Daily T (2019) Ecoworld to unveil malaysia's first robot hotel. https://www.thesundaily.my/local/ecoworld-to-unveil-malaysias-first-robothotel-YF546100, accessed 4 May 2019

11. Den Hertog P, Van der Aa W, De Jong MW (2010) Capabilities for managing service innovation: towards a conceptual framework. J Serv Manag 21(4):490-514

12. Flaherty DH (2008) Reflections on Reform of the Federal Privacy Act. Office of the Privacy Commissioner of Canada

13. government K (2007) Robot ethics charter. https://akikok012um1. wordpress.com/south-korean-robot-ethics-charter-2012/, accessed 26 Sep 2019

14. Hirschi A (2018) The fourth industrial revolution: Issues and implications for career research and practice. Career Dev Quart 66(3):192-204

15. Institute TJB (2017) The joanna briggs institute critical appraisal tools for use in jbi systematic review: Checklists for case reports. http://joannabriggs.org/assets/docs/critical-appraisaltools/JBI_Critical_AppraisalChecklist_for_Case_Reports2017. pdf, accessed 1 Aug 2019

16. Ivanov S, Webster C, Garenko A (2018) Young russian adults' attitudes towards the potential use of robots in hotels. Tech Soc $55: 24-32$

17. Jiangsu Good Point Robot Technology Co L (2018) Installation of intelligent vegetable delivery robot for door-to-door service of hotel restaurant automatic vegetable delivery robot. https://b2b.hc360. com/viewPics/supplyself_pics/82816776170.html, accessed 26 Sep 2019

18. Khan S, Germak C (2018) Reframing hri design opportunities for social robots: Lessons learnt from a service robotics case study approach using ux for hri. Futur Intern 10(10):101

19. Kim JH, Jang S (2016) Determinants of authentic experiences: An extended gilmore and pine model for ethnic restaurants. Int $\mathrm{J}$ Contemp Hosp Manag 28(10):2247-2266

20. Kuo CM, Chen LC, Tseng CY (2017) Investigating an innovative service with hospitality robots. Int J Contemp Hosp Manag 29(5):1305-1321

21. Lab ER (2017) Eureka robotics lab. https://www.cardiffmet.ac.uk/ technologies/Pages/EUREKA-Robotics-Lab.aspx, accessed 26 Jan 2020

22. Leung R (2019) Smart hospitality: Taiwan hotel stakeholder perspectives. Tour Rev 74(1):50-62

23. Lu L, Cai R, Gursoy D (2019) Developing and validating a service robot integration willingness scale. Int J Hosp Manag 80:36-51

24. Ma YL (2013) The searching of decision tree based on data mining. Appl Mech Mater Trans Tech Publ 380:2633-2636

25. METI (2019) Japan's robot strategy was compiled ministry of economy, trade and industry (meti). https://www.meti.go.jp/english/ press/2015/0123_01.html, accessed 4 May 2019

26. Nakanishi J, Kuramoto I, Baba J, Kohei O, Yoshikawa Y, Ishiguro $\mathrm{H}$ (2018) Can a humanoid robot engage in heartwarming interaction service at a hotel? In: Proceedings of the 6th International Conference on Human-Agent Interaction, ACM, pp 45-53

27. Ostrom AL, Parasuraman A, Bowen DE, Patrício L, Voss CA (2015) Service research priorities in a rapidly changing context. J Serv Res 18(2):127-159

28. Parker LE (2018) Creation of the national artificial intelligence research and development strategic plan. AI Magazine 39(2):2532

29. Peters MA et al (2017) Technological unemployment: Educating for the fourth industrial revolution. J Self-Gov Manag Econ $5(1): 25-33$

30. Pfann W, Hagelbarger D (1956) Electromagnetic suspension of a molten zone. J Appl Phys 27(1):12-18

31. Prisecaru P (2016) Challenges of the fourth industrial revolution. Knowl Horiz Econom 8(1):57 
32. Rodriguez-Lizundia E, Marcos S Zalama (2015) A bellboy robot: Study of the effects of robot behaviour on user engagement and comfort. Int J Human-Comp Stud 82:83-95

33. Rokach L, Maimon OZ (2008) Data mining with decision trees: theory and applications, vol 69. World Scientific, Singapore

34. ROLLINGSTONE (2018) The first robot waiter restaurant in malaysia. https://www.goody $25 . \mathrm{com} / \operatorname{mind} 3545820$, accessed 26 Sep 2019

35. Sanbo Z, Jia H (2019) "nobody dining" has no way to go? the robot meets the waterloo! http://www.linkshop.com.cn/web/ archives/2019/417455.shtml, accessed 26 Sep 2019

36. Sanbot Innovation Technology L (2016) Sanbot innovation technology., ltd. http://en.sanbot.com/index, accessed 26 Sep 2019

37. Schwab K (2017) Five leadership priorities for 2017. In: World economic forum, Annual meeting 2017 Davos, WEF

38. Teece DJ (2007) Explicating dynamic capabilities: the nature and microfoundations of (sustainable) enterprise performance. Strat Manag J 28(13):1319-1350

39. Testa MR, Sipe L (2012) Service-leadership competencies for hospitality and tourism management. Int J Hosp Manag 31(3):648-658

40. Theverge (2018) China's e-commerce giant, launched a hotel service robot, space egg. http://www.pig66.com/2018/145_0926/ 17230043.html, accessed 26 Sep 2019

41. Verge T (2019) Japan's robot hotel lays off half the robots after they created more work for humans. https://www.theverge. com/2019/1/15/18184198/japans-robot-hotel-lay-off-work-forhumans, accessed 4 May 2019

42. Wang E (2018) Alibaba's ai unit to launch hospitality robots in october. https://www.chinamoneynetwork.com/2018/09/20/alibabasai-unit-to-launch-hospitality-robots-in-october, accessed 4 May 2019

43. Wei Y (2013) Skills talent development for the next ten years of taiwan. www2.itis.org.tw/pubreport/pubreport_detail.aspx? rpno $=64558015 \&$ chaptername $=\%$ E7\%B5\%90\% E8\%AB $\% 96$ $\% \mathrm{E} 8 \% 88 \% 87 \% \mathrm{E} 6 \% 94 \% \mathrm{BF} \% \mathrm{E} 7 \% \mathrm{AD} \% 96 \% \mathrm{E} 5 \% \mathrm{BB} \% \mathrm{BA} \% \mathrm{E} 8$ $\%$ AD\%B0, accessed 1 Aug 2019
44. Weng YH, Sugahara Y, Hashimoto K, Takanishi A (2015) Intersection of "tokku" special zone, robots, and the law: a case study on legal impacts to humanoid robots. Int J Soc Robot 7(5):841-857

45. Zhang S (2018) Who owns the data generated by your smart car? Harv J Law Technol 32(1):299

Publisher's Note Springer Nature remains neutral with regard to jurisdictional claims in published maps and institutional affiliations.

Jiaji Yang is the Associate Tutor at Cardiff School of Technologies (CST) and the STEM Outreach Lead at EUREKA Robotics lab and a Ph.D. researcher at Cardiff Metropolitan University. He is currently dedicated to researching the application and development of humanoid robots in the hospitality industry.

Dr. Esyin Chew is a Reader in Robotics and Educational Technologies at Cardiff Metropolitan University with the achievement of $\sim £ 450,000$ total grant value, more than 70 research and innovation outputs including quality academic publications, media press engagements, 10 awards, and 3 national policy impact documents. Esyin is the founder of the EUREKA Robotics Lab [www.cardiffmet.ac.uk/eureka] at Cardiff School of Technologies, researching and designing humanoid robotics in education, hospitality, and healthcare. Demonstrating a track record of research and design leadership for cutting edge humanoid robotic programs, with AI capabilities. The UK Parliament Artificial Intelligence Select Committee published her expert viewpoint on the implications of AI, titled: "What are the implications of artificial intelligence? In Love and War [https:// bit.ly/3iC1QDC], as well as the UK Parliament Education Committee's Fourth industrial revolution [https://bit.ly/3lsyFoc] inquiry. 